\title{
Secondary analysis of economic data: a review of cost-benefit studies of neonatal screening for phenylketonuria
}

Joanne Lord, Margaret J Thomason, Peter Littlejohns, Ronald A Chalmers, Murray D Bain, G Michael Addison, A Hervey Wilcox, Carol A Seymour

\begin{abstract}
Study objective-To estimate the net financial benefit of neonatal screening for phenylketonuria (PKU): by a simple pooling of cost data from the literature; and by a more complex modelling approach.

Design-A systematic literature review was conducted to identify papers containing data on the monetary costs and benefits of neonatal screening for PKU. The methodological quality of the studies was appraised, and data were extracted on resource use and expenditure. Monetary data were converted to common currency units, and standardised to UK incidence rates. Net benefits were calculated for median, best case and worst case scenarios, and the effect of excluding poor quality studies and data was tested. The net benefit was also estimated from a model based on data from the literature and assumptions appropriate for the current UK situation. Extensive sensitivity analysis was conducted.
\end{abstract}

Main results-The direct net benefit of screening based on the median costs and benefits from the 13 studies identified was $£ 143400$ per case detected and treated (£39 000 and $£ 241800$ for worst case and best case scenarios respectively). The direct net benefit obtained by the modelling approach was lower at $£ 93400$ per case detected and treated. Screening remained cost saving under sensitivity analysis, except with low residential care costs (less than $£ 12300$ per annum), or very low incidence rates (less than 1 in 27 000).

Conclusions-The economic literature on PKU screening is of variable quality. The two methods of secondary analysis lead to the same conclusion: that neonatal PKU screening is worthwhile in financial terms alone in the UK, and that it justifies the infrastructure for collecting and testing neonatal blood samples. This result cannot necessarily be extrapolated to other countries.

(F Epidemiol Community Health 1999;53:179-186)

Phenylketonuria (PKU) is an inherited disorder that causes severe irreversible neurological impairment, which can however be prevented if a low phenylalanine diet is started before three weeks of age. Accurate neonatal screening tests became available in the early 1960s, and were quickly adopted in most developed countries. The clinical and economic case for screening seemed to be clear: lifelong institutional care could be avoided by means of a simple and cheap test and early treatment.

The case for screening is now known to be more complicated. ${ }^{1}$ When the screening programme was first introduced it was thought that dietary control was necessary for only 5 to 10 years. However, subtle neuropsychological impairment, and in a few cases overt neurological deterioration, has been observed in screen detected and treated children. This deterioration is associated with poor control and early cessation of diet. Thus, recent guidelines have recommended stricter dietary control for life. ${ }^{2}$ Very careful control of phenylalanine levels is now thought necessary before and during pregnancy for women with PKU, to prevent damage to the fetus. In addition, treatment is increasingly recommended for atypical cases of hyperphenylalaninaemia, with blood concentrations above about $400 \mu \mathrm{mmol} / 1$, but below values indicating "classic" PKU $(1200 \mu \mathrm{mmol} /$ 1). The cut off points used for reporting screening results and starting dietary treatment vary internationally.

This paper presents a detailed review and secondary analysis of evidence on the costs and benefits of neonatal screening for PKU, and estimates the economic impact of the new tighter treatment guidelines. ${ }^{2}$ Alternative methods of pooling economic data are explored, and the robustness of the findings examined.

\section{Methods}

A systematic literature review of economic evidence on PKU screening was conducted as part of a broader review of neonatal screening for inborn errors of metabolism. ${ }^{3}$ Search methods included electronic searches of Medline and Embase. Papers were included in the economic review if they contained any data on the cost of neonatal screening for PKU, the cost of treatment and/or the cost of caring for untreated patients. Some papers were excluded from this review because they reported their results in such a way that the costs and benefits of screening for PKU could not be isolated from those of screening for other disorders. Full details of the review methods and excluded papers are given in our project report. ${ }^{3}$ Included papers were critically appraised by two of the authors (JL and PL) using a checklist. The methodological quality of the economic evaluations was assessed using a 
Table 1 Assumptions used in the best estimate model and sensitivity analysis

\begin{tabular}{|c|c|c|c|}
\hline & Best estimate model & Range tested in one way sensitivity analysis & $\begin{array}{l}\text { Distribution for probabilistic sensitivity } \\
\text { analysis }\end{array}$ \\
\hline \multicolumn{4}{|l|}{ A. The screening programme } \\
\hline Detection rate & 9.22 cases detected per 100000 screened $^{9}$ & $0.8^{24}$ to $17.9^{10}$ per 100000 screened & $\mathrm{N}[9.22,9.22]$ truncated at $0^{9}$ \\
\hline Recall rate & $\begin{array}{l}0.15 \% \text { external recall } \text { rate }^{38}-16 \text { recalls per } \\
\text { case detected }\end{array}$ & $3^{24}$ to $276^{18}$ per case detected & $\mathrm{U}[3,29]$ \\
\hline False negative rate & $\begin{array}{l}0.3 \% \text { of cases, based on UK data for } \\
1984-8^{9}\end{array}$ & $0 \%$ to $0.9 \%$ (UK data for $1974-88)^{9}$ & $\mathrm{~N}[0.003,0.003]$ truncated at $0^{9}$ \\
\hline \multicolumn{4}{|c|}{ B. Treatment for cases detected early } \\
\hline Duration of treatment & Life & $5^{16,17}$ to $30^{21}$ years & - \\
\hline Dietary treatment & $\begin{array}{l}\text { 150g Lofenalac pd for first year, } 90 \mathrm{~g} \\
\text { Maxamaid pd age } 1-5,135 \mathrm{~g} \text { Maxamaid } \\
\text { pd age } 6-10 \text {, and then } 162.5 \mathrm{~g} \text { Maxamaid } \\
\text { pd. Plus low protein foods. }\end{array}$ & - & - \\
\hline Follow up care & $\begin{array}{l}13 \text { inpatient (IP) days in first year; } 4 \\
\text { outpatient (OP) visits pa; } 11 \text { blood tests } \\
\text { pa; psychological tests at age } 5 \text { and } 10 . \\
\text { Plus patient expenses and maternity care, } \\
2 \text { pregnancies per woman }(50 \%) \text { at ages } \\
21 \text { and } 24 .{ }^{10}\end{array}$ & $\begin{array}{l}\text { Komrower }{ }^{18}: 7 \text { IP days in first year, } 3 \text { OP } \\
\text { visits pa, } 16 \text { blood tests pa and no } \\
\text { psychological tests.Alm }{ }^{20}: 28 \text { IP days in first } \\
\text { year, then } 7 \text { every other year, } 2 \text { OP visits pa, } \\
30 \text { blood tests pa and } 1 \text { psychological test pa. }\end{array}$ & $\begin{array}{l}\text { IP first year: } U[7,28] . \text { IP pa: } \\
\text { U[0,3.5]. OP visits pa: } U[2,4] . \text { Blood } \\
\text { tests pa: U[16,30]. Psych. tests pa: } \\
\text { U[0,1] }\end{array}$ \\
\hline Survival & $\begin{array}{l}\text { Survival curves based on survey by Fisch } \\
\text { et a }{ }^{39} \text { without treatment, and general UK } \\
\text { population with treatment }{ }^{40}\end{array}$ & $\begin{array}{l}50 \% \text { reduction and } 50 \% \text { increase in the } \\
\text { relative risk of death by age for untreated } \\
\text { patients compared to treated patients }\end{array}$ & $\mathrm{U}[-0.5,0.5]$ \\
\hline \multicolumn{4}{|c|}{ C. Social care for cases not detected early } \\
\hline Special education & $\begin{array}{l}\text { Special education ( } 7 \text { years primary and } 6 \\
\text { years secondary) for } 70 \% \text { of untreated } \\
\text { PKU children, } 30 \% \text { unable to attend. }\end{array}$ & $0 \%$ to $100 \%$ able to attend special school & $\mathrm{U}[0.5,0.9]$ \\
\hline Residential care & $\begin{array}{l}64 \% \text { of children in residential care from } \\
\text { age } 5 \text { to } 17,50 \% \text { of other children in } \\
\text { foster care from age } 5 \text { to } 17^{22} \cdot 64 \% \text { of } \\
\text { adults }(18+) \text { in high dependency } \\
\text { residential care, all other adults in low } \\
\text { dependency residential care }{ }^{22} \text {. }\end{array}$ & $\begin{array}{l}50 \% \text { of children in residential care, no foster } \\
\text { care, } 50 \% \text { of adults in high dependency } \\
\text { residential care, none in low dependency } \\
\text { care. } 100 \% \text { of children and adults in high } \\
\text { dependency residential care. }\end{array}$ & $\begin{array}{l}\text { Child residential care: } \mathrm{U}[0.5,0.78] \text {. } \\
\text { Other children in foster care: } \\
\mathrm{U}[0.25,0.75] \text {. Adults in high } \\
\text { dependency residential care: } \\
\mathrm{U}[0.5,0.78] \text {. Other adults in low } \\
\text { dependency residential care: } \\
\mathrm{U}[0.5,1.0]\end{array}$ \\
\hline \multicolumn{4}{|c|}{ D. Lost productivity for cases not detected early } \\
\hline Parental productivity & $\begin{array}{l}\text { For half the families whose disabled child } \\
\text { is living at home, all earnings are lost for } \\
\text { one parent } t^{22} \text {. }\end{array}$ & $\begin{array}{l}0 \% \text { to } 100 \% \text { of earnings are lost for one } \\
\text { parent }\end{array}$ & $\mathrm{U}[0.25,0.75]$ \\
\hline $\begin{array}{l}\text { Productivity of person } \\
\text { with PKU }\end{array}$ & $\begin{array}{l}83 \% \text { and } 86 \% \text { of earnings lost for } \\
\text { untreated people in age groups } 18-24 \text { and } \\
25-65 \text { respectively. }\end{array}$ & $\begin{array}{l}50 \% \text { to } 100 \% \text { of earnings lost for untreated } \\
\text { individuals }\end{array}$ & $\begin{array}{l}\text { Age } 18-24: \mathrm{U}[0.66,1.00] . \text { Age } 25 \\
\text { plus: } \mathrm{U}[0.72,1.00]\end{array}$ \\
\hline \multicolumn{4}{|l|}{ E. Discount rates } \\
\hline Discount rates & $6 \% \mathrm{pa}$ & $0 \%$ to $10 \%$ & - \\
\hline
\end{tabular}

$\mathrm{N}[\mathrm{m}, \mathrm{s}]$ - Normal distribution with mean $\mathrm{m}$ and variance $\mathrm{s}$.

$\mathrm{U}[\mathrm{x}, \mathrm{y}]$ - Uniform distribution with minimum $\mathrm{x}$ and maximum $\mathrm{y}$.

published index, ${ }^{5}$ which is based on widely accepted criteria. ${ }^{6}$

Two different methods were used for secondary analysis of the economic data. ${ }^{7}$ Firstly, in the "price standardisation" approach, monetary costs and benefits were extracted from the studies, converted to common currency units (1995 UK pounds), standardised to the UK incidence rate, and then pooled. Secondly, in the "modelling" approach, resource utilisation and unit costs were estimated from the literature, national data and current treatment recommendations, from the viewpoint of the UK government. The advantage of this latter approach is that it uses up to date assumptions that are appropriate for the decision making area (in this case the UK).

The following cost data were extracted from the papers: the cost per 100000 babies of sample collection $\left(\mathrm{C}_{1}\right)$, laboratory testing $\left(\mathrm{C}_{2}\right)$, and repeat tests $\left(\mathrm{C}_{3}\right)$; and the cost per case of dietary treatment $\left(\mathrm{C}_{4}\right)$ and of follow up care $\left(\mathrm{C}_{5}\right)$. The benefits comprised: the avoided cost per case detected of special education, health and social care $\left(\mathrm{B}_{1}\right)$; and the avoided loss of productivity for PKU patients and their parents $\left(B_{2}\right)$.

Many countries now use the blood spot samples originally collected for PKU screening to test for other disorders, such as congenital hypothyroidism. Where blood sample collection costs were given in the papers, all of these costs were attributed to PKU, rather than divided between PKU and other disorders. This is a conservative assumption, providing a common basis for comparing study results. It also provides us with a baseline for evaluating extensions of the neonatal screening programme to other disorders - if PKU on its own justifies the infrastructure of collecting and testing neonatal blood samples, then these costs can be ignored in evaluating programme extensions.

"Marginal" costs and benefits were extracted from the papers wherever possible, for instance the costs of caring for a healthy child were subtracted from the cost of caring for an untreated PKU child. Costs borne by patients and employers were included as well as costs to the health and social care sectors.

All extracted costs were converted to 1995 pounds sterling, using official exchange rates for the studies' cost years and the UK retail price index. This has been shown to give very similar results to more complicated methods. ${ }^{7}$ The net benefit per case detected, NB, was then calculated:

$\mathrm{NB}=(1-\mathrm{n}) \times\left(\mathrm{B}_{1}-\mathrm{C}_{4}-\mathrm{C}_{5}\right)-\left(\mathrm{C}_{1}+\mathrm{C}_{2}+\mathrm{C}_{3}\right) / \mathrm{I}$ Where $\mathrm{C}_{1}$ to $\mathrm{C}_{5}$ and $\mathrm{B}_{1}$ are the median values for the cost and benefit categories described above; I is the number of cases of PKU detected per 100000 screened; and $n$ is the number of false negatives per case. There is continuing controversy over the inclusion of 
productivity losses in economic analyses, and over the correct method for valuing them. ${ }^{8}$ For this reason, the net benefit was calculated excluding productivity losses, $\mathrm{B}_{2}$, which are reported separately.

In addition to the financial costs and benefits outlined above, there are intangible costs and benefits that have not been quantified. The intrinsic value of the extra years of life and improved quality of life resulting from screening is high. This will be partially offset by anxiety caused by false positive results, and by the problems that some families experience in maintaining the rigorous diet.

Data from the national PKU register for 1984-88 were used to estimate the detection rate, $I$, of 9.22 cases per 100000 screened, and the false negative rate, $\mathrm{n}$, of 1 of 351 cases. $^{9}$ This detection rate includes 7.2 cases of "classic" PKU (blood phenylalanine concentrations of $1200 \mu \mathrm{mol} / 1$ or over), and two cases of "possibly atypical" PKU (900 to $1200 \mu \mathrm{mol} / \mathrm{l})$. A further 2.5 "atypical" cases (400 to 900 $\mu \mathrm{mmol} / \mathrm{l}) \mathrm{might}$ also be expected. These atypical cases have not been included in our analysis, because, though they would probably receive treatment nowadays, they have a low risk of mental impairment.

It is assumed that no cases would be detected early enough for effective intervention in the absence of a screening programme, and that treatment compliance is $100 \%$.

Net benefits were calculated for a "worst case" scenario using the 75 th percentile for all of the costs and the 25th percentile for the benefits, and for a "best case" scenario using the 25 th and 75 th percentiles respectively. The effect of excluding data of poor methodo- logical quality was tested in two ways. Firstly, the net benefits were calculated excluding studies that scored $50 \%$ or less on the quality index. ${ }^{5}$ Only four studies were judged by the appraisers to meet this criteria (see table 4). Secondly, the net benefits were calculated excluding individual cost estimates $\left(\mathrm{C}_{1}\right.$ to $\mathrm{C}_{5}$, $\mathrm{B}_{1}$ and $\mathrm{B}_{2}$ ) judged to be of poor methodological quality (grade III in table 4). Thus, some data were included from eight of the studies, but full data were included from only two of the studies.

The model was developed by first replicating one of the studies as a form of validation. This was the most recent UK based study. ${ }^{10}{ }^{11}$ It used detailed empirically based costing, and was the only study reported in sufficient detail to allow full replication. A "best estimate" analysis was then conducted by substituting into this model the best quality available data and assumptions to represent the current UK situation, including lifelong diet and follow up care (tables 1 and 2).

All of the studies in the review assumed that people with PKU would not receive dietary treatment in the absence of screening. However, many physicians today would recommend that treatment be started for any children missed by screening when they present clinically, around age $2-3$ say. There is (fortunately) little evidence about the impact of such late treatment, as missed cases are rare. The best estimate model assumes that there would be no treatment in the absence of screening. This is a conservative assumption, which makes screening seem relatively less attractive. It is relaxed in the sensitivity analysis.

Table 2 Unit cost data used in best estimate model

\begin{tabular}{|c|c|c|}
\hline & $\begin{array}{l}\text { Cost per unit } \\
\text { (UK } 1995 £ \text { ) }\end{array}$ & Source and notes \\
\hline \multicolumn{3}{|l|}{ A. Screening } \\
\hline Sample collection per test & 4.82 & Barden $^{22}$ \\
\hline Laboratory test per test & 1.14 & Wright ${ }^{10}$ \\
\hline Repeat test per test & 5.81 & “ \\
\hline \multicolumn{3}{|l|}{ B. Treatment for cases detected early } \\
\hline Inpatient care per day & 165.25 & “ \\
\hline Outpatient care per visit & 19.78 & “ \\
\hline Blood test per test & 1.13 & “ \\
\hline Psychological test per test & 30.23 & “ \\
\hline Diet - Lofenalac per gram & 0.02 & “ \\
\hline Diet - Maxamaid per gram & 0.07 & “ \\
\hline Diet - extras per year & 1123 & “ \\
\hline Patient expenses per year & 558 & “ \\
\hline Maternity care per pregnancy & 12750 & “ \\
\hline \multicolumn{3}{|l|}{ C. Social care for cases not detected early } \\
\hline Mainstream school - primary per year & 1880 & Annual abstract of statistics ${ }^{40}$ \\
\hline Mainstream school - secondary per year & 2590 & \\
\hline Special school per year & 13750 & \\
\hline \multicolumn{3}{|r|}{ NHS and LA residential care for people with learning } \\
\hline Children and high dependency adult per year & 32820 & difficulties - PSSRU estimates ${ }^{41}$. \\
\hline Low dependency adult per year & 23790 & \\
\hline Foster care per year & 21290 & PSSRU estimates $^{41}$ \\
\hline Normal consumption per year & 7150 & Boarding out allowance for foster care - PSSRU estimates ${ }^{41}$ \\
\hline \multicolumn{3}{|l|}{ D. Lost productivity for cases not detected early } \\
\hline \multicolumn{2}{|l|}{ Parental earnings } & Average earnings for mother by age of child adjusted for \\
\hline Child age $0-4$ per year & 3480 & unemployment - employment rates from General Household \\
\hline Child age 5-9 per year & 4770 & survey $^{42}$, average hours and wages from New Earning Survey ${ }^{43}$ \\
\hline Child age $10-17$ per year & 6060 & \\
\hline \multicolumn{2}{|l|}{ Patient's earnings } & Average earnings by age adjusted for unemployment - \\
\hline Age $18-24$ per year & 7740 & employment rates from General Household survey ${ }^{42}$, average \\
\hline Age $25-34$ per year & 7500 & hours and wages from New Earning Survey ${ }^{43}$ \\
\hline Age 35-49 per year & 13390 & \\
\hline Age $50-59$ per year & 6060 & \\
\hline Age $60-64$ per year & 3130 & \\
\hline
\end{tabular}


Table 3 Details of screening programmes on which cost-benefit studies were based

\begin{tabular}{llllcc}
\hline First author & Publication year & Country (region) & $\begin{array}{l}\text { Screening } \\
\text { period }\end{array}$ & $\begin{array}{l}\text { Number of babies } \\
\text { screened }\end{array}$ & $\begin{array}{l}\text { Cases detected / } \\
100 \text { 000 screened }\end{array}$ \\
\hline Cunningham $^{13}$ & 1969 & US (California) & $1966-7$ & 625000 & 6.2 \\
Bush $^{14}$ & 1973 & US (New York State) & $1965-70$ & 1893000 & 6.9 \\
Steiner $^{15}$ & 1973 & US (Mississippi) & \multicolumn{2}{c}{ Based on reported incidence in other states } \\
Webb $^{16}$ & 1973 & Canada (Ontario) & $1966-71$ & 742000 & 6.3 \\
Levy $^{17}$ & 1974 & US (Massachusetts) & $1972 / 3$ & 77000 & $9.1^{\star}$ \\
Komrower $^{18}$ & 1979 & UK (Manchester) & $1969-78$ & 507000 & $13.6^{\star}$ \\
Veale $^{19}$ & 1980 & New Zealand & $1970-80 ?$ & 550000 & 4.8 \\
Alm $^{20}$ & 1982 & Sweden & $1965-79$ & 1326000 & 3.2 \\
Goss $^{21}$ & 1983 & Belgium & $1978-81$ & 561000 & $8.9^{\star}$ \\
Barden $^{22}$ & 1984 & US (Wisconsin) & $1978-82$ & 295000 & 5.8 \\
Dhondt $^{23}$ & 1991 & France (Nord-Pas-de-Calais) & - & $80000 \mathrm{pa}$ & $6.3^{\star}$ \\
Wright $^{10,11}$ & 1990 & UK (Scotland) & 1988 & 67000 & 17.9 \\
Hisashige & 1994 & Japan & $1977-90$ & 18700000 & 0.8 \\
\hline
\end{tabular}

^ PKU and non-PKU hyperphenylalanaemias not distinguished.

However, there is another side to this issue. Estimates of survival, social care and productivity without screening used in previous studies and in our model derive from pre-screening days. We might expect actual outcomes to be better if screening were to be withdrawn today: with dietary treatment started at diagnosis the level of impairment should be lower; and clinical and social care would be better than it would have been 20 to 30 years ago, resulting in less handicap. In addition, even with the early treatment that is made possible by screening, outcomes might not be quite as good as initially envisaged. Thus, the marginal benefits of screening are exaggerated in our model. Again, these factors are investigated through sensitivity analysis.

Two forms of sensitivity analysis were used..$^{12}$ Firstly, variables were adjusted, one at a time, to upper and lower limits and the impact on the overall results was noted (one way sensitivity analysis). The maximum and minimum values used here were derived from the range of values in the literature, or were estimated by the authors (see table 1).

Secondly, Monte Carlo simulation was used to estimate the variation in the model's results because of uncertainty over input variables (probabilistic sensitivity analysis). For each variable a probability distribution was assumed (table 1). So, for example, the number of cases detected per 100000 neonates screened was treated as a normally distributed random variable with mean and variance of 9.22 (an approximation for the Poisson process). The number of inpatient days in the first year for cases detected through screening was treated as a uniformly distributed random variable with minimum 7 and maximum 28 (the range reported in previous studies). Values for each variable were then randomly sampled from the assumed distributions and the resulting costs and benefits calculated. This sampling procedure was repeated a large number of times, $n$, each iteration providing a set of estimated costs and benefits. From this series of $\mathrm{n}$ simulated results, standard errors and hence confidence intervals were estimated. The number of iterations, $n$, was increased until the standard errors appeared to stabilise.

\section{Results}

Thirteen cost-benefit analyses of PKU screening were identified. ${ }^{10}{ }^{13-24}$ They were published over a 25 year period and used data from screening programmes in eight different countries (table 3). Detection rates varied from 0.8 cases per 100000 screened in Japan ${ }^{24}$ to 17.9 cases in Scotland. ${ }^{10}$ These differences are broadly in line with expectations resulting from underlying population incidences, though in some cases sample sizes were small and definitions of PKU varied.

Assumptions about treatment, care, and outcomes varied widely. The duration of diet treatment ranged from 5 to 30 years. The average duration of institutionalisation assumed for untreated people ranged from 20 to 30 years. Only three studies used empirically derived life tables for people with untreated PKU. ${ }^{1420} 22$

Table 4 Methodological quality of cost-benefit studies

\begin{tabular}{|c|c|c|c|c|c|c|c|c|c|c|c|}
\hline & \multirow[b]{2}{*}{$\begin{array}{l}\text { Viewpoint } \\
\text { (a) }\end{array}$} & \multirow[b]{2}{*}{$\begin{array}{l}\text { Discount } \\
\text { rate }\end{array}$} & \multirow{2}{*}{$\begin{array}{l}\text { Variables in } \\
\text { sensitivity } \\
\text { analysis }\end{array}$} & \multicolumn{7}{|c|}{ Grade of cost estimates (b) } & \multirow[b]{2}{*}{$\begin{array}{l}\text { Quality index } \\
\text { score (c) }\end{array}$} \\
\hline & & & & $\begin{array}{l}\text { Sample collection } \\
C_{1}\end{array}$ & Lab tests $C_{2}$ & Recalls $C_{3}$ & $\operatorname{Diet} C_{4}$ & Follow up $C_{5}$ & Care $B_{1}$ & $\begin{array}{l}\text { Productivity } \\
B_{2}\end{array}$ & \\
\hline US 69 & $\mathrm{H}^{\star}$ & - & - & - & - & - & III & - & III & - & $16 \%$ \\
\hline US $73 a$ & $\mathrm{H}^{\star}$ & $4 \%$ & - & II & II & III & II & - & III & - & $65 \%$ \\
\hline US $73 \mathrm{~b}$ & $\mathrm{~S}^{\star}$ & $4 \% \dagger$ & - & - & - & - & III & III & III & III & $34 \%$ \\
\hline Can 73 & $\mathrm{H}^{\star}$ & - & - & - & III & - & III & III & III & - & $22 \%$ \\
\hline US 74 & $\mathrm{H}^{\star}$ & - & - & II & II & II & III & III & III & - & $22 \%$ \\
\hline UK 79 & $\mathrm{P}^{\star}$ & - & - & - & II & II & II & II & II & - & $34 \%$ \\
\hline NZ 80 & $\mathrm{H}^{\star}$ & $10 \%$ & 1 & III & III & III & III & - & III & - & $41 \%$ \\
\hline Sw 82 & $\mathrm{~S}^{\star}$ & $6 \%$ & 6 & II & - & - & II & II & II & III & $63 \%$ \\
\hline Bel 83 & S & $4.18 \%$ & 2 & - & - & - & III & - & III & III & $47 \%$ \\
\hline US 84 & $S^{\star}$ & $7 \%$ & 2 & I & I & I & I & I & I & I & $63 \%$ \\
\hline Fra 91 & $S$ & $4.5 \%$ & 1 & - & - & - & III & III & II & III & $41 \%$ \\
\hline UK 90 & $S^{\star}$ & $6 \%$ & - & - & I & I & I & I & II & II & $63 \%$ \\
\hline Jap 94 & S & $7 \%$ & 1 & II & II & II & II & II & II & I & $50 \%$ \\
\hline
\end{tabular}

(a) H, Health care sector (public or private); P, public sector; S, societal. (b) I, All main resources included and sound costing methods; II, minor omissions in items included and/or minor inadequacies in costing methods; III, major omissions in items included or major inadequacies in costing methods. (c) Adams $e t$ al $1992^{5}$. ${ }^{\star}$ Not stated explicitly in paper. $†$ Discounting applied to indirect benefits only, not to direct costs or benefits. 


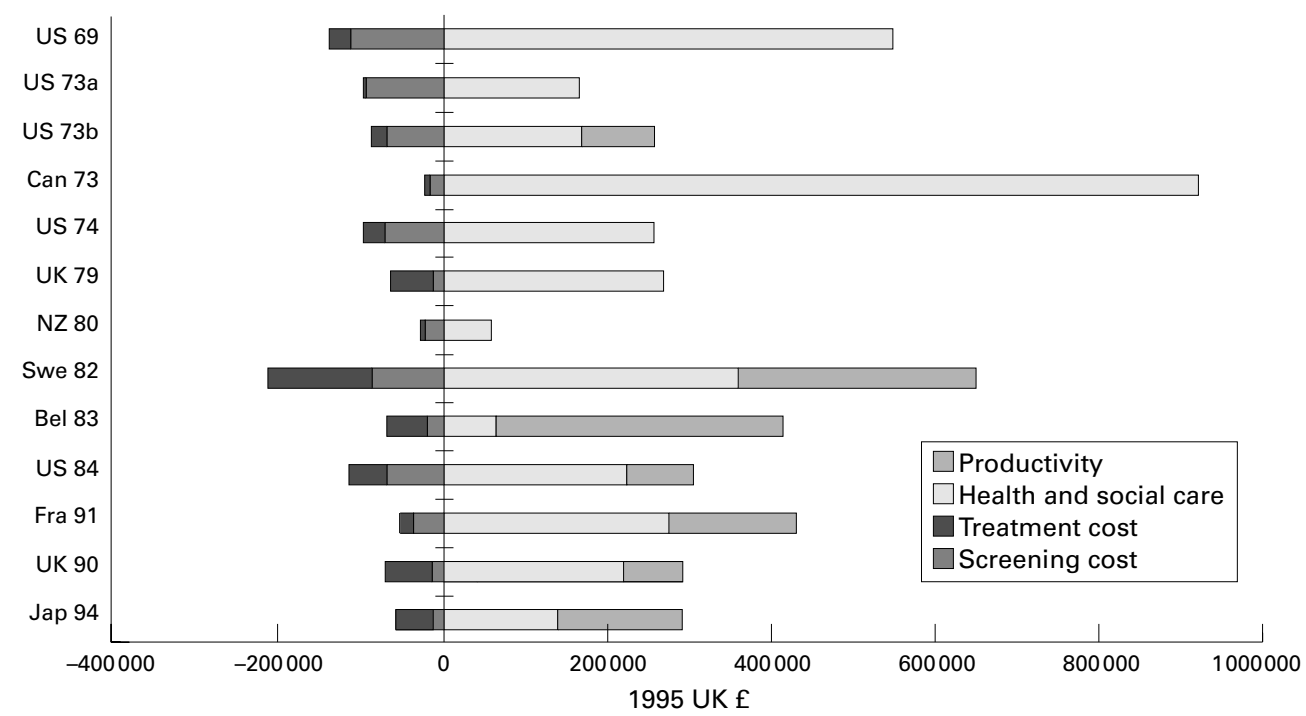

Figure 1 Costs and benefits per case detected and treated for detection rate of 9.22 cases per 100000 screened.

The rest assumed a life expectancy without treatment, which ranged from 30 to 65 years.

None of the studies attempted to quantify the intangible benefits of improved life expectancy or quality of life in monetary terms. Bush et $a l^{14}$ estimated that each case of PKU detected and treated would save 47 quality adjusted life years, QALYs (14 when discounted at $4 \%$ per annum).

The methodological quality of the studies was very variable (table 4). Only three papers $^{212324}$ explicitly stated the viewpoint for their analyses. The costing methods used were generally weak: with omission of important items, such as sample collection costs; inadequate reporting of the sources of resource utilisation and cost estimates; and failure to report methods of overhead allocation and capital costing. Four studies ${ }^{13}{ }^{16-18}$ failed to discount costs or benefits at all, and one discounted productivity losses but not other costs or benefits. ${ }^{15}$ The use of sensitivity analysis was particularly poor; only one paper ${ }^{20}$ reported that more than two parameters had been varied. Four studies $^{10142022}$ scored over $50 \%$ on the methodological quality index. ${ }^{5}$

Although there were large differences in the reported results, all studies concluded that the benefits of screening outweigh the costs (fig 1). The net benefit per case detected and treated based on the median costs and benefits was $£ 143400$, with an extra $£ 153100$ avoided productivity losses (table 5). The net benefit remained positive under the worst case scenario. Excluding poor quality studies and data made little difference to the overall results, though the difference between worst case and best case scenarios was reduced (fig 2).

The model successfully replicated the Wright study ${ }^{10}$ (less than $1 \%$ difference in the net benefit and in the productivity gain).

The best estimate analysis gave a net benefit of $£ 93400$ per case detected and treated, with an extra $£ 52900$ from avoided productivity losses (table 5). This amounts to a direct annual saving of $£ 6.5 \mathrm{~m}$ in the UK (with 70 cases per annum ${ }^{9}$ ). Standard errors were estimated for the costs and benefits by probabilistic sensitivity analysis (table 5 ). The simulation results had stabilised by 2000 iterations (between $n=1000$ and $n=2000$ the standard error for the net benefit fell by only $0.8 \%$ ). The simulation yielded confidence intervals for the net benefit of $£ 91800$ to $£ 95000$.

If it is assumed that without screening children would start diet and follow up care at diagnosis (roughly age 3) onwards, then the marginal cost of treatment falls to $£ 13100$ per case and the net benefit rises to £175 100 . However, as discussed above, this figure does not allow for improvements in health outcomes that would probably have arisen without the institution of screening because of improved treatment and care.

Table 5 Results of secondary analysis (1995 UK \&s per case detected and treated)

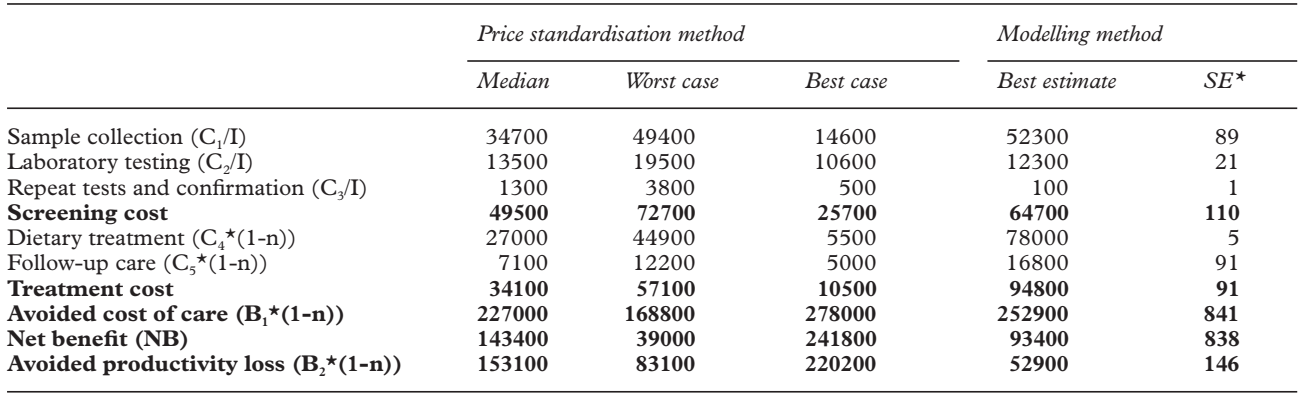

* Standard error estimated by probabilistic sensitivity analysis (Monte Carlo Simulation) with 2000 iterations. 


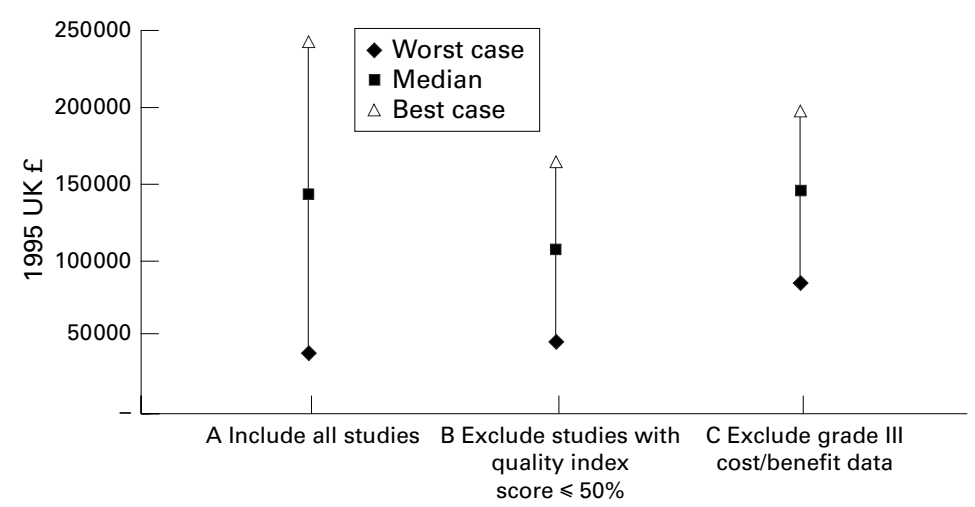

Figure 2 Net benefit per case detected and treated by price standardisation method.

If diet and follow up is maintained for only 18 years, rather than for life, the model yields a net benefit of $£ 128300$ per case. So the MRC Working Party ${ }^{2}$ recommendation of lifelong treatment may be estimated to cost around $£ 35000$ per case; $£ 2.4 \mathrm{~m}$ per annum for the UK. This might well be justified by a reduced risk of neurological damage, but there is currently no evidence on this.

The net benefit remained positive under one way sensitivity analysis, with the following two exceptions. Firstly, the net benefit fell below zero with a unit cost of residential care below $£ 12300$ per annum. Secondly, with a detection rate below 3.77 cases per 100000 - which will occur in many countries. ${ }^{19}$ Even here, screening is still likely to be cost effective. With an incidence of 1 in 125000 births (as in Japan) screening and treatment would cost about $£ 586600$ more than the avoided cost of care $(£ 12500$ per undiscounted QALY, or $£ 41900$ per QALY with discounting).

\section{Discussion}

This review supports the conclusion that the methodological quality of the economic evaluation literature is very mixed. ${ }^{52-31}$ Recent initiatives, such as the publication of guidelines on the conduct and reporting of economic evaluations, ${ }^{32}$ should lead to improvement. In the meantime, decision makers need to be able to separate the good economic analyses from the bad, particularly if quantitative metaanalyses of cost data are to be performed. There are well developed structured qualitative checklists, ${ }^{29} 33$ but these lack an overall scoring system. The index used in this study ${ }^{5}$ requires validation before it can be generally accepted.

Two alternative methods for pooling cost data have been suggested, price standardisation and modelling. ${ }^{7}$ Consideration of the source of variations between studies is important in deciding how to summarise their results. ${ }^{12}$ The majority of economic evaluations are nonstochastic: cost data are not estimated at an individual patient level, so intra-study estimates of sampling variation are not possible. We now recognise that PKU presents as a spectrum of disease. Outcomes, and hence costs, vary considerably between people both with and without screening. However, deter-
KEY POINTS

- The methodological quality of the economic evaluation literature on PKU screening is very mixed.

- All of the cost-benefit studies identified concluded that PKU screening is worthwhile in financial terms alone, although estimates of the net monetary benefits varied widely.

- A simple pooling of cost data from the papers led to a higher estimate of the net benefit of screening than a more complex modelling approach, which included up to date and local data and assumptions and removed methodological heterogeneity.

- Screening for PKU is cost saving in the $\mathrm{UK}$, and on its own justifies the cost of collecting neonatal blood samples, which are also used for other screening tests. This result is robust to changes in assumptions about treatment and outcomes.

- For countries with a low incidence of PKU and/or low costs of caring for handicapped persons, screening may not be cost saving. However, it is possible that even in these situations screening might still be cost effective.

ministic models, such as those presented here, are based simply on average costs and outcomes. In this context, variation between studies might be useful as an indication of sampling variation.

However, there are other possible sources of variation. Clinical practice, service utilisation, unit costs, and population characteristics all vary over time and between countries and regions. This "environmental variation" between studies may or may not be desirable, depending on the purpose of evaluation. The aim of our review was to inform UK policy, so estimates of current UK costs and consequences were required. Modelling allows for the inclusion of up to date local data and assumptions-removing environmental variation. However, this might not always be appropriate. From a US Federal government perspective, for example, estimates based on studies in a number of states might be desirable.

Further variation in study estimates arises from the use of different analytical techniques-different costing methods or discount rates, for example. This "artefactual variation" is problematic as it does not reflect real world differences and may introduce systematic biases. As far as possible artefactual sources of variation should be eliminated when pooling cost data. Methodological standardisation is best done through modelling, as data reporting is rarely sufficient to allow this to be done retrospectively. For instance, unless a paper presents costs broken down by year, it is not possible to recalculate total costs using a different discount rate. 
No conclusions can be drawn about the relative scale of environmental and artefactual variation between the studies in the review and our model. It is not possible to disentangle variation because of different assumptions from variation because of different methods. Fortunately, both of the methods of secondary analysis used in this study clearly suggest that, in countries such as the UK with a relatively high incidence of PKU, screening is actually cost saving. This remains the case even allowing for the lifelong treatment and follow up care that is now recommended. ${ }^{2}$ For countries with a lower PKU incidence, screening might well still be cost effective, because of intangible benefits not included in our analysis.

$\mathrm{Alm}^{34}$ found that 9 of 23 children with PKU increased their tolerance of phenylalanine and were able to normalise their diet between 1 and 10 years of age. If this applied in the UK, with no adverse health effects, an additional annual saving of around $£ 1.7 \mathrm{~m}$ could be generated $(£ 62300$ per case assuming cessation of diet at age 6 but continuation of follow up for life).

Neonatal blood samples are also used to test for other inherited disorders, such as congenital hypothyroidism, and there is increasing pressure to extend neonatal screening further, for instance to include cystic fibrosis. As the costs of collecting neonatal blood samples are fully justified for PKU alone, these costs do not need to be considered when evaluating the cost effectiveness of screening for other disorders using these same samples.

There is currently much interest in a new method for analysing neonatal blood samples using tandem mass spectrometry (tandem MS). ${ }^{35}$ This technology is at least as accurate as traditional methods for PKU testing, probably more so, and has the advantage that certain other inborn errors of metabolism can be detected simultaneously. ${ }^{36}$ Tandem MS might be justified on cost grounds for PKU alone if established in large efficient laboratories. A recent review ${ }^{37}$ estimated the laboratory cost of tandem MS screening at $£ 1.20$ per test, roughly $£ 13000$ per case of PKU detected, which is very close to our estimates of the cost of current screening methods (table 5). However, this figure is based on a laboratory throughput of 100000 newborns per annum, which is currently met by only one laboratory in the UK. Trials of tandem MS screening are now indicated to establish its cost in practice, and careful consideration is needed to establish whether any additional costs are justified by the detection of other metabolic disorders.

Funding: this work forms part of a project funded by the NHS Health Technology Assessment programme. Conflicts of interest: none.

This model was largely based on data from a dissertation by $M$ Wright, supervised by Richard Brooks and Professor Forrester Cockburn. We thank Alastair Fischer for his very helpful advice on an earlier draft of this paper.

1 MRC Working Party on Phenylketonuria. Phenylketonuria due to phenylalanine hydroxylase deficiency: an unfolding story. BMF 1993;306:115-19.
2 MRC Working Party on Phenylketonuria. Recommendations on the dietary management of phenylketonuria. Arch tions on the dietary man
Dis Child $1993 ; 68: 426-7$.

3 Pollitt RJ, Green A, McCabe CJ, et al. Newborn screening for inborn errors of metabolism: a systematic review. Health Technol Assess 1997;1.

4 Thomason MJ, Lord J, Bain MD, et al. A systematic review of evidence for the appropriateness of neonatal screening programmes for inborn errors of metabolism. 7 Public Health Med 1998;20:331-43.

5 Adams ME, McCall NT, Gray DT, et al. Economic analysis in randomized control trials. Med Care 1992;30:231-43.

6 Drummond MF, Stoddart GL, Torrance GW. Methods for the economic evaluation of health care programmes. Oxford: Oxford University Press, 1987.

7 Jefferson T, Mugford M, Gray A, et al. An exercise on the feasibility of carrying out secondary economic analysis. Health Econ 1996;5:155-65.

8 Koopmanschap MA, Rutten RFH. The impact of indirect costs on outcomes of health care programs. Health Econ 1994;3:385-93.

9 Smith I, Cook B, Beasley M. Review of neonatal screening programme for phenylketonuria. BMF 1991;303:333-5.

10 Wright M. An evaluation of the cost benefit analysis approach A case study: a CBA of the screening and treatment of $P K U$. [MSc Thesis]. Glasgow: University of Strathclyde, 1990.

11 Cockburn F, Clark BJ, Byrne A, et al. Maternal phenylketonuria - diet, dangers and dilemmas. International Paediatrics 1992;7:67-74.

12 Briggs A, Sculpher MJ, Buxton MJ. Uncertainty in the economic evaluation of health care technologies: the role of sensitivity analysis. Health Econ 1994;3:95-104

13 Cunningham GC. Two years of PKU testing in California. The role of the laboratory. Californian Medicine 1969;110: 11-16.

14 Bush JW, Chen MM, Patrick DL. Health status index in cost effectiveness: analysis of PKU program. In: Berg, ed. Health status indexes. New York: Hospital and Educational Trust, 1973:172-209.

15 Steiner KC, Smith HA. Application of cost-benefit analysis to a PKU screening program. Inquiry 1973;10:34-40.

16 Webb JF. PKU screening, is it worth it? Can Med Assoc 7 1973;108:328-9.

17 Van Pelt A, Levy H. Cost-benefit analysis of newborn screening for metabolic disorders. $N$ Engl F Med 1974;291: 1414-16.

18 Komrower GM, Sardharwalla IB, Fowler B, et al. The Manchester regional screening programme: a 10-year exercise in patient and family care. $B M \mathcal{F} 1979 ; 2: 635-8$.

19 Veale AMO. Screening for hereditary metabolic disorders. Screening for Phenylketonuria. In: Bickle H, Guthrie R, Hammersen G, eds. Neonatal screening for inborn errors of metabolism. New York: Springer-Verlag, 1980:7-18.

20 Alm J, Larsson A, Rosenqvist U. Health economic analysis of the Swedish neonatal metabolic screening programme: a method of optimizing routines. Med Decis Making 1982;2: $33-45$.

21 Goss S. Cost-benefit analysis of the detection and treatment of phenylketonuria (PKU) in newly-born babies, in Belgium. Cahiers Economique de Bruxelles 1983;459-68.

22 Barden HS, Kessel R, Schuett VE. The costs and benefits of screening for PKU in Wisconsin. Soc Biol 1984;31:1-17.

23 Dhondt J-L, Farriaux J-P, Sailly J-C, et al. Economic evaluation of cost-benefit ratio of neonatal screening procedure for phenylketonuria and hypothyroidism. F Inherit Metab Dis 1991;14:633-9.

24 Hisashige A. Health economic analysis of the neonatal screening program in Japan. Int 7 Technol Assess Health Care 1994;10:382-91.

25 Udvarhelyi IS, Colditz GA, Rai A, et al. Cost-effectiveness and cost-benefit analyses in the medical literature. Are the methods being used correctly? Ann Intern Med 1992;116: 238-44.

26 Rutten-van Molken MP, van Doorslaer EK, Rutten FF. Economic appraisal of asthma and COPD care: a literature review 1980-91. Soc Sci Med 1992;35:161-75.

27 Evers SMAA, Van Wijk AS, Ament AJHA. Economic evaluation of mental health care interventions. A review. Health Econ 1997;6:161-77.

28 Jefferson T, Demicheli V. Is vaccination against hepatitis B efficient? A review of world literature. Health Econ 1994;3: 25-37.

29 Mason J, Drummond MF. Reporting guidelines for economic studies. Health Econ 1995;4:85-94.

30 Briggs A, Sculpher MJ. Sensitivity analysis in economic evaluation: a review of published studies. Health Econ evaluation: a revic

31 Jacobs P, Bachynsky J. Costing methods in the Canadian literature on the economic evaluation of health care: A survey and assessment. Int $\mathcal{F}$ Technol Assess Health Care 1996;12: 721-34.

32 Russell LB, Gold MR, Siegel JE, et al. The role of cost-effectiveness analysis in health and medicine. FAMA 1996;276:1172-7.

33 Centre for Reviews and Dissemination. Making costeffectiveness information accessible: the NHS economic evaluation database project. CRD guidance for reporting critical summaries of economic evaluations. CRD Report Number 6. York: NHS Centre for Reviews and Dissemination, Yniversity of York, 1996.

34 Alm J, Bodegard G, Larsson A, et al. Children with inborn errors of phenylalanine metabolism: prognosis and phenylalanine tolerance. Acta Paediatr Scand 1986;75:619-25. 
35 Sweetman L. Newborn screening by tandem mass spectrometry (MS-MS). Clin Chem 1996;42:345-6.

36 Chace DH, Millington DS, Terada N, et al. Rapid diagnosis of phenylketonuria by quantitative analysis for phenylalanine and tyrosine in neonatal blood spots by tandem mass spectrometry. Clin Chem 1993;39:66-71.

37 Pollitt RJ, Green A, McCabe CJ, et al. Neonatal screening for inborn errors of metabolism: cost, yield and outcome. Health Technol Assess 1997;1.

38 Lubenow N, Diepenbrock F, Schickling H, et al. Phenylketonuria screening with a fluorometric microplate assay. Eur f Clin Chem Clin Biochem 1994;32:525-8.
39 Fisch R, Bilek OM, Bruhl HH. Causes of death of institutionalized phenylketonuric (PKU) patients - a institutionalized phenylketonuric (PKU)
national survey. Minn Med 1976;53:306-9.

40 Office for National Statistics. Annual abstract of statistics. Office for National Statistics. Annual

41 Netten A, Dennett J. Unit costs of health and social care 1996. Canterbury: PSSRU University of Kent, 1996

42 Bennett N, Jarvis L, Rowlands O, et al. Living in Britain: Results from the 1994 General Household Survey. Office of Population Censuses and Surveys, Social Survey Division. London: HMSO, 1996.

43 Office for National Statistics. New Earnings Survey 1996. London: HMSO, 1996. 